\title{
Effect of Paddle-Shaft Position on the Dissolution Rate of Sodium Diclofenac Tablets and the Equivalence Assessment of a Generic Product
}

\author{
Mari Fujimoto ${ }^{1,2, *}$, Kiyoshi Mihara ${ }^{2,3,{ }^{*},}$ James A. Jorgenson ${ }^{4}$, Kuniko \\ Otsuka ${ }^{5}$, Masaki Aburada ${ }^{2,3}$, Tomie Kawada ${ }^{3}$, Junko Ishizaki', \\ Ken-ichi Miyamoto ${ }^{1}$, and Makoto Otsuka ${ }^{3,6}$ \\ 'Graduate School of Natural Science and Technology, Kanazawa University, Kakuma, \\ Kanazawa, 920-1192, Japan \\ ${ }^{2}$ Research Center for Clinical Pharmacy, Faculty of Pharmacy, Musashino University, \\ Shinmachi 1-1-20, Nishitokyo, Tokyo, 202-8585, Japan \\ ${ }^{3}$ Research Institute of Pharmaceutical Sciences, Faculty of Pharmacy, Musashino University, \\ Shinmachi 1-1-20, Nishitokyo, Tokyo, 202-8585, Japan \\ ${ }^{4}$ Department of Hospital Pharmacy, University of Utah, 50 North Medical Drive, Room A050 SLC, \\ UT 84132-5901 \\ ${ }^{5}$ Yokohama College of Pharmacy, Matano-cho 601,Totsuka, Yokohama 245-0066, Japan
}

\begin{abstract}
Dissolution testing is useful for controlling the quality of oral products and rejecting bioinequivalent products. However, several sources of variability in dissolution tests can affect evaluations of quality. The purpose of this study was to investigate the effects of paddle-shaft position on the dissolution rates of a brand-name (BR) and four genericequivalent (GE), rapid-release tablets of sodium diclofenac. The paddle was shifted $5 \mathrm{~mm}$ from the center of the vessel, and the dissolution profiles were compared with that obtained at the central position. Although the GEs had a wide range of variability and significantly different dissolution profiles, they were estimated to be equivalent to the BR when the paddle was set at the center of the vessel. The 5-mm-shifted position significantly increased the dissolution rates of all products with the result that some GEs did not meet the criteria for equivalence.

In conclusion, paddle position is potentially a cause of error in GE equivalence assessments. The paddle should be accurately positioned at the center of the vessel in dissolution tests for the equivalence assessment of GEs.
\end{abstract}

\section{INTRODUCTION}

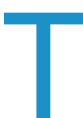

he use of generic-equivalent (GE) drugs reduces medical and health-care costs. However, the market share of GEs in Japan is less than in other developed countries (1). While $96 \%$ of consumers supported GE usage in a questionnaire provided by the Japan Fair Trade Commission in September 2006 (2), $54 \%$ of physicians questioned their quality (3). Therefore, quality assurance is extremely important to eliminate anxiety about the usage of GEs in Japan.

GEs must be as safe and effective as brand-name medicines (BRs) and bioequivalent to BRs in human in vivo pharmacokinetic studies. Dissolution testing is a useful tool for the quality control of oral products, and it provides important information concerning bioequivalence. However, there are several sources of variability in dissolution testing such as temperature, $\mathrm{pH}(4,5)$, and aeration (6) of the test medium; rotation and agitation of the paddle shaft $(4,7,8)$; sample position $(4,9)$; sample

${ }^{6}$ Corresponding author.

*These authors contributed equally to this report. storage conditions (6); and analytical methods (10), which potentially affect decision errors of quality evaluation. Qualification of the test apparatus and procedures is required. Therefore, it is necessary to develop a reliable and precise dissolution test method that is sensitive enough to detect slight differences between GE and BR. In this study, we investigated whether moving the paddle-shaft axis from the center affects the rate of dissolution. Precision glass vessels were used to exclude the effect of the vessel factor on tablet dissolution profiles. Sodium diclofenac in rapid-release tablets was chosen as the model drug and dosage form, because it is highly soluble in water, and its pharmacological effect appears so rapidly that the dissolution rate of the tablet may affect the therapeutic effect of the drug.

\section{MATERIALS AND METHODS \\ Materials}

Bulk powder sodium diclofenac was purchased as a standard material from Sigma Chemical Co. The drugs tested in this study were Voltaren as a reference and four GEs. All products were rapid-release dosage forms that 


\begin{tabular}{|c|c|c|c|c|c|}
\hline Code & Brand Name & Package & Lot No. & Exp. & Company \\
\hline BR & Voltaren Tab. & PTP & P0005 & $\begin{array}{l}\text { Nov } \\
2008\end{array}$ & $\begin{array}{l}\text { CIBA-GEIGY(Japan)/ } \\
\text { Novartis Pharma }\end{array}$ \\
\hline GE1 & Saffrac Tablets & PTP & 112503 & $\begin{array}{l}\text { Nov } \\
2007\end{array}$ & NIPPON SHINYAKU \\
\hline GE2 & Sofarin & PTP & 1703 & $\begin{array}{l}\text { Jan } \\
2009\end{array}$ & NIPPON CHEMIPHAR \\
\hline GE3 & DAISPAS Tab. & PTP & SP06311 & $\begin{array}{l}\text { Aug } \\
2008\end{array}$ & $\begin{array}{l}\text { Fuso Pharmaceutical } \\
\text { Industries/Daito } \\
\text { Pharmaceutical }\end{array}$ \\
\hline GE4 & BOLABOMIN & PTP & 3052 & $\begin{array}{l}\text { Jan } \\
2008\end{array}$ & $\begin{array}{l}\text { MERCK HOEI/ } \\
\text { Tsuruhara } \\
\text { Pharmaceutical }\end{array}$ \\
\hline
\end{tabular}

contained $25 \mathrm{mg}$ of sodium diclofenac. Information on these tablets is summarized in Table 1. These drugs are all currently on the market in Japan. All were stored at room temperature before use, and the testing was performed before product expiration.

\section{Dissolution Tests}

Dissolution tests were carried out by the paddle methods listed in the JP 15 (11) and the Japanese Orange Book (12). A dissolution apparatus (NTR-VS6P, Toyama Sangyo Co. Ltd., Osaka, Japan) fitted with an autosampler (TCP-61C) was used. Performance qualification (PQ) was accomplished by the USP Performance Verification Test (PVT) with USP prednisone calibrator tablets. Pure water obtained from a reverse-osmosis membrane water system was kept at $45^{\circ} \mathrm{C}$ to deaerate for $2 \mathrm{~h}$ before use. The position of a tablet dropped at the bottom of the vessel was determined visually. Each test was conducted with a set of six tablets at $50 \mathrm{rpm}$ using $900 \mathrm{~mL}$ of deaerated water at $37 \pm 0.5^{\circ} \mathrm{C}$.

Precision glass vessels, which have uniform bottom curvature and inner surface regularity (Takao Manufacturing Co., Ltd., Kyoto, Japan), were used to minimize the vessel figure factor $(13,14)$. The vessels have an inner diameter of $100.06 \pm 0.08 \mathrm{~mm}$ in the cylinder and a radius of $50.03 \pm 0.08 \mathrm{~mm}$ in the hemispheric portion. They provide test results that are reproducible and less variable. The dissolution apparatus was adjusted to a horizontal position using a level gauge. The paddle shafts were set at the center of the vessels (center position) and the position was confirmed using a center gauge (Toyama Sangyo Co., Ltd., Osaka, Japan).

To investigate the influence of their positions, the paddles were moved $5 \mathrm{~mm}$ from the center along the vessel bottom (5-mm-off position). We had already carried out a pilot study that showed a significant difference in the dissolution rate of the calibrator tablet between the center and 3-mm-shifted paddle conditions. To detect

\section{Central Position}

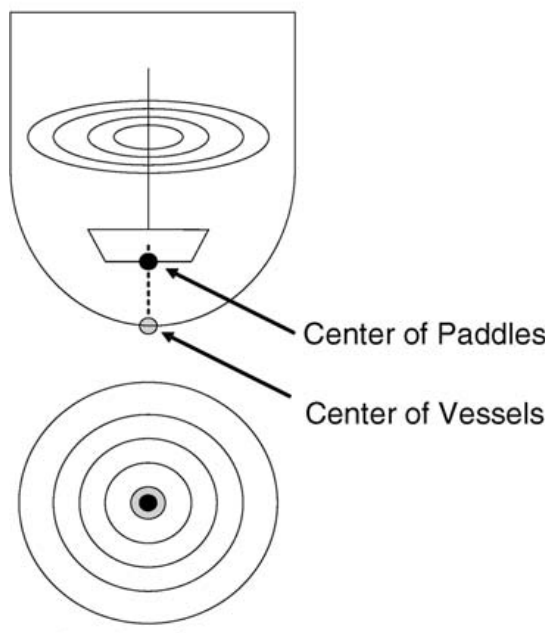

Laminar flow 5-mm-off Position
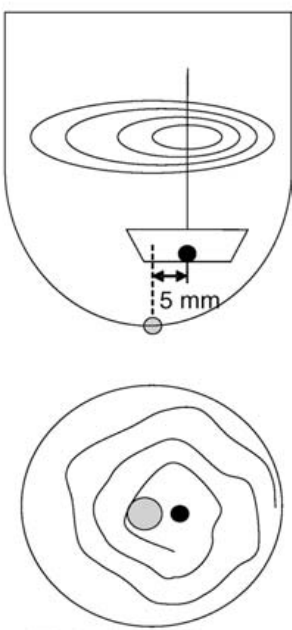

Turbulent flow
Figure 1.Schematic diagram of deviation in the paddle-shaft position and medium flow in the vessels.

the clear effect of the shifted paddle position, we moved the paddle $5 \mathrm{~mm}$ (Figure 1).

\section{Sampling and Measurement of the Sodium Diclofenac Solution}

Samples were collected at 3, 6, 9, 12, 15, 18, 20, 25, 30, $35,40,50,60,70$, and $80 \mathrm{~min}$ and filtered using polyester fiber, 20-30 um (F72, Toyama Sangyo Co., Ltd., Osaka, Japan). The initial volume was maintained by the addition of water. Sodium diclofenac concentrations were determined using a UV spectrophotometer (UV-2550, Shimadzu Co. Ltd., Kyoto, Japan) at $276 \mathrm{~nm}$. Absorbance values were converted to percent dissolved values using a standard curve.

\section{Acceptance Criterion for Dissolution Tests}

The acceptable mean percent dissolved at $20 \mathrm{~min}$ is $85 \%$ or more in the Japanese Orange Book (12).

\section{Acceptance Criteria for Equivalence of Dissolution Profiles}

To evaluate differences in dissolution patterns between $\mathrm{BR}$ and GEs, $f_{2}$ values were calculated. This factor is a logarithmic transformation of the sum of the squared error

$$
f_{2}=50 \cdot \log \left\{\left[1+1 / n \sum_{i=1}^{n}\left(T_{i}-R_{i}\right)^{2}\right]^{-0.5} \times 100\right\}
$$

where $T_{i}$ is the test data (mean percent dissolved value of the GE) at time point $i, R_{i}$ is the reference data (mean percent dissolved of $\mathrm{BR}$ ) at time point $i$, and $n$ is the 




* Significantly different from that of BR $(P<0.05)$.

Figure 2. Dissolution profiles of diclofenac at the central position. The dotted line represents the acceptance criterion ( $85 \%$ in $20 \mathrm{~min}$ ) for diclofenac tablets specified by JP 15. The results are expressed as the mean $\pm S D(n=6)$.

number of time points ( $n=3$ at 15, 30, and $40 \mathrm{~min}$ ). The factor is 100 when the reference and test profiles are identical and approaches zero as the dissimilarity increases. In the guideline for bioequivalence studies of generic products (15), products are judged to be equivalent in dissolution rate when the average dissolution from the reference product reaches $85 \%$ between 15 and $30 \mathrm{~min}$; the average dissolved amount from the test product does not deviate by more than $15 \%$ from that of the reference product at two time points when the average amounts dissolved from the reference product are around 60 and $85 \%$. When $f_{2}$ is used, the value should not be less than 42 . This guideline is similar to "Guideline for Bioequivalence Studies for Different Strengths of Oral Solid Dosage Forms" (16).

\section{Statistical Analysis}

To compare the BR and GE dissolution data, a one-way analysis of variance (ANOVA) was carried out followed by the Tukey-Kramer multiple-range test or Scheffe's F-test (17). To determine whether there were any differences between the central and 5-mm-off positions, Student's $t$-test was used. When the data did not show a normal distribution, the homogeneity of variances, Welch's $t$-test, was performed. The differences were considered significant at $P<0.05$.

\section{RESULTS}

\section{Dissolution Characteristics at the Central Position}

Dissolution profiles of BR and GEs obtained when the paddle was positioned at the center of the vessel are shown in Figure 2. The profiles show wide variability and significant differences among the products, especially during the early phase of dissolution (0-15 min). GE2 and GE4 started dissolving quickly with $20-30 \%$ dissolved at 3 min, whereas BR, GE1, and GE3 showed a delay in dissolution.
Table 2. Percent Dissolved, Judgment, and $f_{2}$ Factor for Sodium Diclofenac Products

\begin{tabular}{|c|c|c|c|c|c|}
\hline \multirow[b]{3}{*}{ BR } & $\begin{array}{l}\% \text { Dissolved } \\
\text { at } 20 \text { min }^{a}\end{array}$ & $\begin{array}{l}\% \text { Dissolved } \\
\text { at } 12 \mathrm{~min}^{b}\end{array}$ & $\begin{array}{c}\% \text { Dissolved } \\
\text { at } 18 \mathrm{~min}^{b}\end{array}$ & $\boldsymbol{f}_{2}$ factor $^{\mathrm{c}}$ & \multirow{3}{*}{$\begin{array}{c}\text { Judgmen } \\
-\quad \text { Pass }\end{array}$} \\
\hline & \multicolumn{4}{|c|}{$($ mean $\pm S D)$} & \\
\hline & $87.1 \pm 4.3$ & $64.3 \pm 10.0$ & 85.4 & 62.9 & \\
\hline GE1 & $94.9 \pm 2.3$ & $90.9 \pm 8.2$ & $95.8 \pm 2.6$ & $50.0 \pm 4.8$ & Pass \\
\hline GE2 & $90.9 \pm 1.1$ & $92.4 \pm 1.9$ & $91.9 \pm$ & $55.2 \pm 2.2$ & Pass \\
\hline GE3 & $88.4 \pm 4.1$ & $51.0 \pm 10.1$ & $82.1 \pm 6.6$ & $60.5 \pm 15.2$ & Pass \\
\hline GE4 & $89.0 \pm 8.1$ & $82.6 \pm 12.6$ & $89.2 \pm 9.0$ & $58.1 \pm 10.3$ & Pass \\
\hline \multicolumn{6}{|c|}{$\begin{array}{l}\text { Acceptance criteria: } \\
\text { a } 85 \% \text { dissolution within } 20 \text { min. } \\
{ }^{b} \text { Mean } \% \text { dissolved of GEs does not deviate by more than } 15 \text { percentage } \\
\text { points from that of BR at time points when the mean } \% \text { dissolved of BR } \\
\text { is around } 60 \% \text { and } 85 \% \text { ( } 12 \text { min and } 18 \text { min). } \\
{ }^{c} f_{2} \text { value of } 42 .\end{array}$} \\
\hline
\end{tabular}

At 3 and 6 min, the order based on mean values was $\mathrm{GE} 2>\mathrm{GE} 4>\mathrm{BR}>\mathrm{GE} 1>\mathrm{GE} 3$. After 6 min, the dissolution of GE1 accelerated, and the order at 15 and 18 min was GE1 > GE2 > GE4 > BR > GE3. At 20 min, each product was over $85 \%$ dissolved, as shown in Table 2 . Therefore, all products met the acceptance criterion ( $85 \%$ dissolution within $20 \mathrm{~min}$ ). The $f_{2}$ values calculated using the 15-, 30-, and 40-min time points in the dissolution tests carried out at the central position are listed in Table 2. The $f_{2}$ values of all products were greater than 42 , and all products were judged equivalent to BR.

The mean percent dissolution of BR (central position) was $64.3 \pm 10.0 \%$ at $12 \mathrm{~min}$ and $85.4 \pm 5.9 \%$ at $18 \mathrm{~min}$ (Table 2). At 12 min, GE1, GE2, GE3, and GE4 were $90.9 \pm 8.2 \%, 92.4 \pm 1.9 \%, 51.0 \pm 10.1 \%$, and $82.6 \pm 12.6 \%$ dissolved, respectively (Table 2). GE3 was $51.0 \pm 10.1 \%$ dissolved, a value that does not deviate by more than $15 \%(49.3-79.3 \%)$ from that of BR $(64.3 \%)$, meeting the equivalence criterion. However, the mean dissolution rates of GE1, GE2, and GE4 at 12 min deviated from that of BR by more than $15 \%$.

At $18 \mathrm{~min}, \mathrm{GE} 1, \mathrm{GE} 2, \mathrm{GE3}$, and GE4 were $95.8 \pm 2.6 \%$, $91.9 \pm 1.2 \%, 82.1 \pm 6.6 \%$, and $89.2 \pm 9.0 \%$ dissolved, respectively. The mean rates of dissolution for GE1, GE2, GE3, and GE4 did not deviate by more than $15 \%$ (70.4-100.4\%) from that of BR (85.4\%), meeting the equivalence criterion. Therefore, GE3 met both of the criteria.

\section{Effect of 5-mm Shaft Offset on the Dissolution Profile}

Figure 3 illustrates the dissolution profiles for BR and GE2. The 5-mm-offset condition increased the rate of dissolution. Table 3 gives the percent dissolution up to $20 \mathrm{~min}$ at the central and 5-mm-off positions. The same phenomenon was observed for all products until $12 \mathrm{~min}$, with GE2 and GE4 showing significant increases in the 5-mm-off condition. 


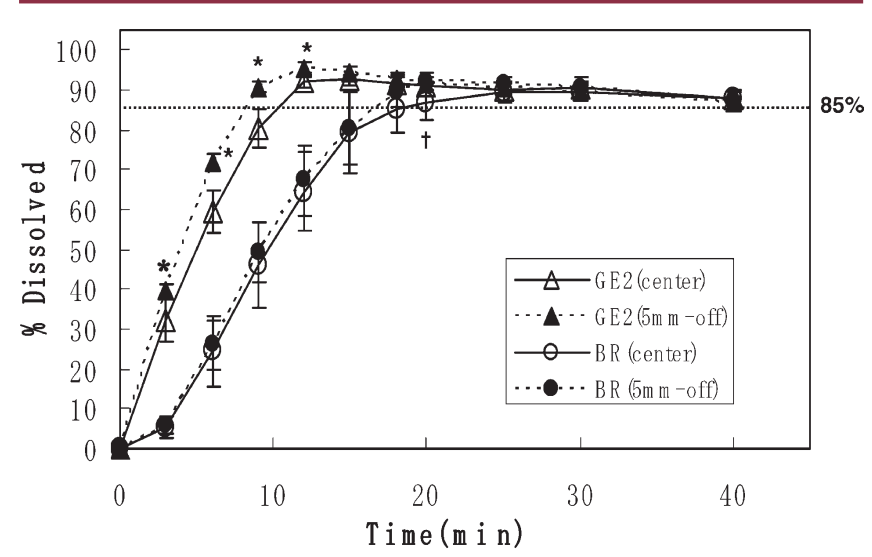

* Significantly different from that of the central position for GE2 $(P<0.05)$. $\uparrow$ Significantly different from that of the central position for BR $(P<0.05)$.

Figure 3. Dissolution profiles of diclofenac at the central and 5-mm-off positions for BR and GE2. The dotted line represents the acceptance criterion (85\% in 20 min) for diclofenac tablets specified by JP 15. Results are expressed as the mean $\pm S D(n=6)$.

However, even in the 5-mm-off condition, all products passed the criterion of $85 \%$ dissolution at $20 \mathrm{~min}$, and the $f_{2}$ values of GEs were also equal to or greater than 42 (data not shown). The mean percent dissolution of BR at 12 min was $67.4 \pm 8.9 \%$, higher than that at the center (Table 3). The value for GE3 at 12 min was $51.0 \%$ at the central position, which deviated by more than $15 \%$ from that of BR in the 5-mm-offset condition (52.4-82.4\%)
(Table 4). When the results obtained at the central position were used, GE3 was judged to be equivalent to BR. But based on the results obtained at the 5-mm-off position, GE was judged to be not equivalent to BR. Therefore, the paddle position affected the quality evaluation.

\section{Effect of 5-mm Offset on the Difference in Percent Dissolved}

Tables 3 and 5 show the effects of paddle position on the difference in percent dissolution between $B R$ and $G E$ products. The mean values for BR were compared with those for GEs at the center and 5-mm-off positions, with (+) denoting a significant difference and (-) denoting no significant difference. The effect of offsetting the shaft could be detected when the result at the center changed.

The difference in dissolution between GE and BR under accurate conditions was checked. For GE1, there was a significant difference at $12 \mathrm{~min}$. For GE2 and GE4, there were significant differences at 3, 6, 9, and $12 \mathrm{~min}$. For GE3, there was a significant difference at $6 \mathrm{~min}$, as shown in Tables 3 and 5.

The dissolution of BR at the central position was significantly different from that of GE1 at 9, 18, and $20 \mathrm{~min}$ and GE3 at $6 \mathrm{~min}$ at the 5-mm-off position, as shown in Table 3.

Compared with the result for BR at the 5-mm-off position, the results for GE3 at 9 min and for GE4 at 9 and $12 \mathrm{~min}$ at the central position were changed (Table 5). At the 5-mm-off position, the results for GE1 at 9 min and

Table 3. Comparison of Percent Dissolved of Generic Products with Those of Brand Product

\begin{tabular}{|c|c|c|c|c|c|c|c|c|c|c|}
\hline & \multicolumn{2}{|c|}{ BR } & \multicolumn{2}{|c|}{ GE1 } & \multicolumn{2}{|c|}{ GE2 } & \multicolumn{2}{|c|}{ GE3 } & \multicolumn{2}{|c|}{ GE4 } \\
\hline & center & $5 \mathrm{~mm}$ & center & $5 \mathrm{~mm}$ & center & $5 \mathrm{~mm}$ & center & $5 \mathrm{~mm}$ & center & $5 \mathrm{~mm}$ \\
\hline \multicolumn{11}{|c|}{$3 \mathrm{~min}$} \\
\hline & 5.3 & 5.8 & 2.6 & 5.9 & $32.1^{*+}$ & $39.4^{* \dagger}$ & 0.3 & $0.7^{+}$ & $19.7^{*+}$ & $21.2^{*+}$ \\
\hline SD & 2.8 & 2.1 & 1.6 & 2.8 & 5.2 & 1.7 & 1.0 & 1.1 & 2.6 & 4.3 \\
\hline \multicolumn{11}{|c|}{$6 \mathrm{~min}$} \\
\hline & 24.4 & 26.1 & 21.7 & 34.1 & $59.7^{*+}$ & $71.9^{*+}$ & $11.0^{*+}$ & 16.5 & $44.5^{*+}$ & $48.6^{*+}$ \\
\hline SD & 8.7 & 6.1 & 7.7 & 9.9 & 5.4 & 2.0 & 4.9 & 8.5 & 6.1 & 4.2 \\
\hline \multicolumn{11}{|c|}{$9 \mathrm{~min}$} \\
\hline & 46.0 & 49.3 & 60.8 & $74.3^{* \dagger}$ & $80.2^{* \dagger}$ & $90.7^{* \dagger}$ & $31.2^{\dagger}$ & 37.6 & $64.6^{*}$ & $70.7^{*+}$ \\
\hline SD & 10.8 & 7.6 & 12.0 & 8.7 & 4.9 & 1.4 & 8.0 & 8.1 & 9.3 & 4.2 \\
\hline \multicolumn{11}{|c|}{$12 \mathrm{~min}$} \\
\hline & 64.3 & 67.4 & $90.9^{*+}$ & $94.8^{*+}$ & $92.4^{*+}$ & $95.2^{* \dagger}$ & 51.0 & 56.4 & $82.6^{*}$ & $87.9^{*+}$ \\
\hline SD & 10.0 & 8.9 & 8.2 & 5.0 & 1.9 & 1.5 & 10.1 & 8.0 & 12.6 & 4.4 \\
\hline \multicolumn{11}{|c|}{$18 \mathrm{~min}$} \\
\hline & 85.4 & 89.6 & 95.8 & $96.8^{*}$ & 91.9 & 92.8 & 82.1 & 81.7 & 89.2 & 93.9 \\
\hline SD & 5.9 & 4.1 & 2.6 & 0.9 & 1.2 & 1.7 & 6.6 & 7.6 & 9.0 & 2.7 \\
\hline \multicolumn{11}{|c|}{$20 \mathrm{~min}$} \\
\hline & 87.1 & 92.0 & 94.9 & $95.6^{*}$ & 90.9 & 91.7 & 88.4 & 86.3 & 89.0 & 93.1 \\
\hline SD & 4.3 & 2.3 & 2.3 & 0.8 & 1.1 & 1.7 & 4.1 & 6.8 & 8.1 & 2.5 \\
\hline
\end{tabular}

* Significantly different from mean dissolved rate (\%) of BR (central position).

† Significantly different from mean dissolved rate (\%) of BR (5mm-off position).

Dissolution Technologies | NOVEMBER 2009 
Table 4. Effect of Paddle Position on Acceptance Criteria for Equivalence of Dissolution Profiles

\begin{tabular}{|c|c|c|c|}
\hline & \multirow[b]{3}{*}{ Center } & \multicolumn{2}{|c|}{ BR } \\
\hline & & Center & $5 \mathrm{~mm}$ off \\
\hline & & $64.3 \%$ (49.3-79.3\%) & $67.4 \%$ (52.4-82.4\%) \\
\hline GE1 & $90.9 \%$ & NE & NE \\
\hline GE2 & $92.4 \%$ & NE & NE \\
\hline GE3 & $51.0 \%$ & $\mathrm{E}$ & NE \\
\hline GE4 & $82.6 \%$ & NE & NE \\
\hline
\end{tabular}

E: equivalent to $B R$

$\mathrm{NE}$ : not equivalent to $\mathrm{BR}$

Table 5. Effect of Paddle Position on Dissolution Rates for BR and GE Products

\begin{tabular}{|c|c|c|c|c|c|c|}
\hline & $3 \mathrm{~min}$ & $6 \mathrm{~min}$ & $9 \mathrm{~min}$ & $12 \mathrm{~min}$ & $18 \mathrm{~min}$ & $20 \mathrm{~min}$ \\
\hline \multicolumn{7}{|c|}{ BR (Center) vs GE (Center) } \\
\hline GE1 & - & - & - & + & - & - \\
\hline GE2 & + & + & + & + & - & - \\
\hline GE3 & - & + & - & - & - & - \\
\hline GE4 & + & + & + & + & - & - \\
\hline \multicolumn{7}{|c|}{ BR (Center) vs GE (5 mm off) } \\
\hline GE1 & - & - & $-\rightarrow+$ & + & $-\rightarrow+$ & $-\rightarrow+$ \\
\hline GE2 & + & + & + & + & - & - \\
\hline GE3 & - & $+\rightarrow-$ & - & - & - & - \\
\hline GE4 & + & + & + & + & - & - \\
\hline \multicolumn{7}{|c|}{ BR (5 mm off) vs GE (Center) } \\
\hline GE1 & - & - & - & + & - & - \\
\hline GE2 & + & + & + & + & - & - \\
\hline GE3 & - & + & $-\rightarrow+$ & - & - & - \\
\hline GE4 & + & + & $+\rightarrow-$ & $+\rightarrow-$ & - & - \\
\hline \multicolumn{7}{|c|}{ BR (5 mm off) vs GE (5 mm off) } \\
\hline GE1 & - & - & $-\rightarrow+$ & + & - & - \\
\hline GE2 & + & + & + & + & - & - \\
\hline GE3 & $-\rightarrow+$ & $+\rightarrow-$ & - & - & - & - \\
\hline GE4 & + & + & + & + & - & - \\
\hline
\end{tabular}

+ Significantly different from mean dissolved rate (\%) of BR.

- Not significantly different from mean dissolved rate (\%) of BR.

for GE3 at 3 and 6 min were changed. The shift in position affected the statistical significance between GE and BR. The experiments suggest that the position of the paddle affects the evaluation of quality and bioequivalence.

\section{DISCUSSION}

Recent dissolution variance studies conducted by the United States Pharmacopeia (USP) suggested glass vessels and apparatus to be a major cause of variability in results. An irregular inner shape altered the flow dynamics and could disturb the conical shape formed by tablet particles, resulting in extensive variation in data. Tanaka et al. (13) reported that precision glass vessels (14), which have no apparent deviation of actual interior vessel shape, gave reproducible and less variable results, regardless of the vessel and position.

The purpose of the present study was to clarify the effects of paddle position on dissolution test results and to develop an accurate method of testing based on reported studies. Therefore, precision glass vessels were used to reduce variability. The effect of paddle position on dissolution testing of GEs was investigated by comparing results between the center and an eccentric position. The dissolution rates for the central and 5-mm-off positions were significantly different, with the latter being significantly higher than the former (Table 3 ). The results are consistent with previous reports $(9,18-20)$, since the rate of dissolution increased significantly when the shaft was offset 2-10 $\mathrm{mm}$ from the central axis of the vessel. The increase in dissolution rate could be explained by the difference in agitation force at the position used. The fluid flow at the center of the vessel is laminar with the slowest and weakest flow. As the position moves away from the center, the fluid resistance may increase and make a turbulent fluid flow, which can also cause the dissolution rate to increase $(8,19)$.

Early on, Cox and co-workers at FDA (18) emphasized the necessity of a laminar, nonturbulent fluid flow in the dissolution vessel. Kaneniwa et al. (21) reported differences in the dissolution process between laminar and turbulent fluid flows. The study suggested that the active energy of dissolution is greater for turbulent than for laminar fluid flow. This could be one of the reasons for the intrabatch variation in the dissolution rates of solid oral dosage forms. The 5 -mm-off position leads to significant differences in the dissolution rates of GE and BR and affects the quality evaluation of GEs (Table 4). This study suggests that the paddle shaft should be adjusted accurately to the center of precision glass vessels in dissolution tests. The JP requirement that the rotating shaft and axis of the dissolution vessel coincide within $\pm 2 \mathrm{~mm}$ defines centering.

\section{CONCLUSIONS}

The 5-mm-off position significantly increased the dissolution rate of all tablets with the result that some GEs did not meet the criteria for equivalence. The paddle position should be accurately adjusted to the center of the vessel in dissolution tests for GEs. Further studies are being conducted to understand the influence of paddle movement on both the hydrodynamics within the vessel 
and the amount of drug dissolved during dissolution testing. The results of such studies may lead to more specific tolerance guidelines for variability.

\section{ACKNOWLEDGMENTS}

This work was supported by grants from MEXT.HAITEKU (2004-2008). The authors would like to thank Toyama Sangyo Co., Ltd. and Takao Manufacturing Co., Ltd. for experimental materials.

\section{REFERENCES}

1. Japan Generic Medicines Association. http://www.jga. gr.jp/medical/generic01.html (accessed Oct 16, 2009).

2. Japan Fair Trade Commission. http://www.jftc.go.jp/ kenkyukai/dk-kondan/06092702.pdf (accessed Oct 15, 2008).

3. The Asahi Shimbun. The Asahi Shimbun Company, Tokyo, Oct 26, 2006; p 17.

4. Mabuchi, H.; Horiike, H.; Owada, K.; Sano, H.; Nagano, T.; Morikawa, K. Study on the Standard of Drug Dissolution Testing (Part 1) -Confirmation of Issues. Bull. Shizuoka Inst. Environ. Hyg. 1999, 42, 69-72.

5. Owada, K.; Horiike, A.; Ueta, A.; Fujiwara, A.; Yamaguchi, Z.; Ukishima, Y.; Mabuchi, H. Study on the Reliability in Drug Dissolution Test (Part 3) Accumulated Sample and Acidity or Alkalinity of Sample Solutions. Bull. Shizuoka Inst. Environ. Hyg. 2002, 44, 31-34.

6. Owada, K.; Horiike, A.; Ueta, A.; Fujiwara, A.; Yamaguchi, Z.; Ukishima, Y.; Mabuchi, H. Study on the Reliability in Drug Dissolution Test (Part 2)Investigation of Variations in the Dissolution Test. Bull. Shizuoka Inst. Environ. Hyg. 2002, 44, 27-30.

7. Watarai, M.; Suzuki, H. Calibration of Dissolution Apparatus-Effects of Deviation of the Paddle Shaft Axis from the Center on the Dissolution Rates of Drugs from Commercial Tablets. Pharm. Regul. Sci. 2002, 33 (1), 8-16.

8. Kaniwa, N. Typical variability in dissolution testing and its qualification. Pharm Tech Jpn. 2002, 18 (11), 1865-1871.

9. Kamba, M.; Seta, Y.; Takeda, N.; Hamaura, T.; Kusai, A.; Nakane, H.; Nishimura, K. Measurement of agitation force in dissolution test and mechanical destructive force in disintegration test. Int. J. Pharm. 2003, 250, 99-109.

10. Yunoki, E. Comparison of Dissolution Rates Between Two Kinds of Dissolution Equipment. Ann. Report Toyama Prefectural Inst. Pharm. Res. 1999, 16, 28-32.

11. Japanese Pharmacopoeia, 15th ed.; Ministry of Health, Labour, and Welfare: Tokyo, Japan, 2007.

12. Orange Book No. 1. Society of Japanese Pharmacopoeia: Tokyo, Japan, 1999. http:// www2.jp-orangebook.gr.jp/data/04/04_03/04_03_ Diclofenac_Sodium.pdf (accessed Oct 17, 2009).

13. Tanaka, M.; Fujiwara H.; Fujiwara, M. Effect of the Irregular Inner Shape of a Glass Vessel on Prednisone Dissolution Results. Dissolution Technol. 2005, 12 (4), 15-19.

14. The High Precision Glass Vessel. Takao Manufacturing Co., Ltd. http://www.takao-mnf.co.jp/vessel_en.html (accessed Oct 17, 2009).

15. Guideline for Bioequivalence Studies of Generic Products; National Institute of Health Sciences, Division of Drugs: Tokyo, Japan, Nov 24, 2006. http:// www.nihs.go.jp/drug/be-guide/GL061124_BE.pdf (accessed Oct 26, 2009).

16. Guideline for Bioequivalence Studies for Different Strengths of Oral Solid Dosage Forms; National Institute of Health Sciences, Division of Drugs: Tokyo, Japan, 2000. http://www.nihs.go.jp/drug/ be-guide\%28e\%29/strength/strength.pdf (accessed Oct 17, 2009).

17. Yanai, K. Four Steps of Excel Statistics, 2nd ed.; OMS Press: Tokorozawa, Japan, 2004.

18. Hanson, R.; Gray, V. Handbook of Dissolution Testing, 3rd ed.; Dissolution Technologies, Inc.: Hockessin, DE, 2004; $p 23$.

19. Qureshi, S. A.; Shabnam, J. Cause of high variability in drug dissolution testing and impact on setting tolerances. Eur. J. Pharm. Sci. 2001, 12, 271-276.

20. Gao, Z.; Moore, T. W.; Smith, A. P.; Doub, W. H.; Westenberger, B. J. Studies of Variability in Dissolution Testing with USP Apparatus 2. J. Pharm. Sci. 2007, 96 (7), 1794-1801.

21. Kaneniwa, N.; Otsuka, M.; Ichikawa, J.; Hayashi, T.; Hayashi, K.; Umezawa O. Dissolution Behavior of Indomethacin Polymorphs in Disk-State. Yakugaku Zasshi 1987, 107 (4), 308-314. 